\title{
Dynamic properties of steel structures under different construction stages, ambient temperature and live load
}

\author{
Fuat Aras (Main Author) \\ Department of Civil Engineering, Faculty of Engineering and Natural Sciences, Istanbul Medeniyet University \\ Dumlupınar D100 Karayolu No:98, 34720, Üsküdar, Istanbul (Turkey) \\ fuat.aras@medeniyet.edu.tr \\ Orcid ID: 0000-0002-2560-4607
}

Işıl Sanrı Karapınar (Corresponding Author)

Department of Civil Engineering, Faculty of Engineering and Natural Sciences, Maltepe University

Marmara Eğitim Köyü, 34857, Maltepe, Istanbul (Turkey)

isilkarapinar@maltepe.edu.tr

Orcid ID: 0000-0002-3695-5867

Manuscript Code: 21421

Date of Acceptance/Reception: 12.03.2021/16.09.2020

DOI: 10.7764/RDLC.20.1.163

\begin{abstract}
Operational modal analysis (OMA), assessing the effect of environmental conditions on the structures has been attracting widespread interest and its results have been used for the validation of numerical models. This paper aims to validate the application of OMA on steel buildings to investigate their dynamic behavior during and after their construction. In this context, the construction stages of a steel building were monitored. With the completion of the construction, the dynamic tests were applied at different times to identify the changes in the modal characteristics of the building with respect to the temperature and service loads. Finally, the analytical model of the building was performed and the building's dynamic properties were determined numerically. As a result, the experimentally obtained dynamic properties for the completed building were compared to those derived from numerical analysis. The results underlined the importance of slab construction for the formation of building behavior in the construction stages. Besides the effects of ambient temperature and service load on the dynamic properties of steel buildings were revealed. Finally, the lack of partition walls in the numerical model has been grasped as the main reason behind the differences between the experimentally and numerically obtained dynamic properties.
\end{abstract}

Keywords: Steel buildings; dynamic properties; construction stages; ambient temperature; operational modal analysis.

Introduction

Recently, the modal testing of structural systems has been attracting considerable interest in civil engineering to determine the dynamic properties of existing structures. This method provides engineers the opportunity to estimate the actual behavior of structures in a direct, practical, and economic way. Due to these advantages, experimental modal analysis has been widely used especially in structural and earthquake engineering. Named as the Operational Modal Analysis (OMA) or Ambient Vibration Survey (AVS), the technique is employed for the investigation of different problems for different types of structures in the literature (Macdonald \& Daniell, 2005; Bayraktar et al., 2008; Chellini et al., 2010; Shiradhonkar \& Shrikhande, 2011; Sevim, Altunışık \& Bayraktar, 2012; Consuegra \& Santos, 2015; Gentile, Saisi \& Cabboi, 2015). Among these studies, Macdonald \& Daniell (2005) monitored a cable-stayed bridge during its construction and identified the modal parameters of the bridge by the ambient vibration measurements. As a result of the study, the variations between the numerical and experimental results were evaluated and discussed.

Also, Bayraktar et al. (2008) reported the importance of modal testing by an application on highway bridges determining the dynamic properties by the vibration measurements taken from the bridges. In another study, Chellini et al. (2010) carried out experimental research on a high ductile steel-concrete composite frame for the damage analysis using vibration measurements and modal identification analyses. By the application of experimental modal analysis, the dynamic response of the frame at different damage states was obtained. Similarly, Shiradhonkar \& Shrikhande (2011) studied the damage detection in a moment resistant frame by the vibration-based system identification and based on the vibration response data, the finite element model was updated. Moreover, Sevim, Altunışık \& Bayraktar (2012) investigated the earthquake behavior of an arch dam by the results of AVS and the analytical model of the dam was calibrated, accordingly. After the calibration, natural frequencies and mode shapes obtained from the experimental and analytical models were compared and the results were discussed.

Consuegra \& Santos (2015) carried out a structural identification process through the dynamic monitoring of a bridge and compared the measured and calculated natural frequencies. Depending on the test results, the model was 
calibrated and the flexural and torsional modes were evaluated for the bridge. In another study, Gentile, Saisi \& Cabboi (2015) proposed a procedure for historic masonry towers based on OMA. Two series of ambient vibration modal tests were performed for a masonry historic bell tower to calibrate its numerical model based on the modal parameters. The use of OMA in determining the dynamic properties of steel structures is one of the various application areas in which the method is used. In the literature, it is seen that many attempts have been made to conduct OMA on steel structures for the correct assessment of modal parameters (Brincker \& Ventura, 2015; Ni, Lu \& Lu, 2017; Zhang et. al, 2019). Since the modal parameters acquired from the ambient vibration survey reveal the operational conditions of the structures, by the use of OMA, the analysis of the obtained data can be done and the dynamic properties can be assessed.

With this motivation, in a study presented by Ni, Lu \& Lu (2017), a full-scale field test was conducted for a high-rise steel building to investigate its dynamic performance and the Bayesian method was used to perform the modal identification. Also, Zhang et al. (2019) employed the Bayesian method to perform OMA for a super tall steel-concrete composite building and evaluated the obtained modal parameters by the results of the other methods. In another study, experiments on the semi-rigid connections over two steel columns and one simple steel frame test specimens were conducted in the laboratory (Türker et al., 2009). Brace effects and damping issues were also investigated on the laboratory test specimens by OMA (Türker \& Bayraktar, 2011, 2013; Kudu et al., 2015). In another study, for the application of OMA in existing steel structures, a 19-story steel building was examined (Shakib \& Parsaeifard, 2011). AVS was applied and numerical analysis was performed for the dynamic properties of the building.

The discrepancies between the experimentally and numerically obtained dynamic properties were pointed out, despite the performed model tuning. For the application of OMA for monitoring studies, ambient vibration measurements taken on three different construction stages of an 18-story building were analyzed (Torkamani \& Ahmadi, 1988). The added effects of nonstructural elements on dynamic frequencies and mode shapes were studied. In a more recent study, Aras (2016) applied ambient vibration tests to a three-story steel building and compared its modal frequencies by the help of numerical and experimental results. The variation of modal frequencies of the building was monitored and the results revealed a strong interaction between two adjacent buildings despite the existing structural joint.

In the present study, OMA was applied to a three-story building within a university complex during and after its construction. The construction of the steel structural system started in August of 2014 and was completed in September 2015. During this time interval, four sets of acceleration measurements were taken at different levels of construction and analyzed for the dynamic identification of the studied building. After the completion of the building, it was used as the main educational building of the university. In the current study, the sensitivity of the dynamic properties of steel buildings to the ambient temperature and service loads which were absent in the earlier studies were investigated. The results of four OMAs applied under different temperatures and the same level of service loads were compared to identify, how the dynamic properties of steel buildings varied with respect to ambient temperature. Similarly, the results of two OMAs applied under two different service loads and the same ambient temperature were compared to identify the response of steel buildings to the increased level of service loads.

For this purpose, one of the OMAs was applied on a regular school day, while the second was applied when the conference hall in the building was partially occupied with a conference going on. As the last step of the investigation, the analytical model of the building was constructed and its dynamic properties were obtained numerically. In order to validate the modal parameters obtained from the numerical analysis, the results are compared with the parameters obtained on field measurements and the differences were interpreted.

Methodology

\section{Studied building and the principles of OMA}

The studied building, named Building $\mathrm{C}$, is one of the steel buildings planned to be located on a $10000 \mathrm{~m}^{2}$ building complex of Istanbul Medeniyet University in Istanbul, Turkey. The whole complex and Building C are shown in Figure 1. As seen from Figure 1, the building is completely separated from the other two structures. The three-story building has dimensions of $66.9 \mathrm{~m}$ by $29 \mathrm{~m}$ and a total area of $6000 \mathrm{~m}^{2}$. The maximum bay lengths are $10 \mathrm{~m}$ and $9 \mathrm{~m}$ in $\mathrm{X}$ and $\mathrm{Y}$ directions, respectively and the story height is $4.2 \mathrm{~m}$ for each story. It also contains a conference hall through the second and third stories of the building. Since the conference hall is accessible from the second story and set an incline through the third floor, this large hall causes slab discontinuity in the second-floor level. 
Figure 1. View of the building complex of Istanbul Medeniyet University. (Self-Elaboration).

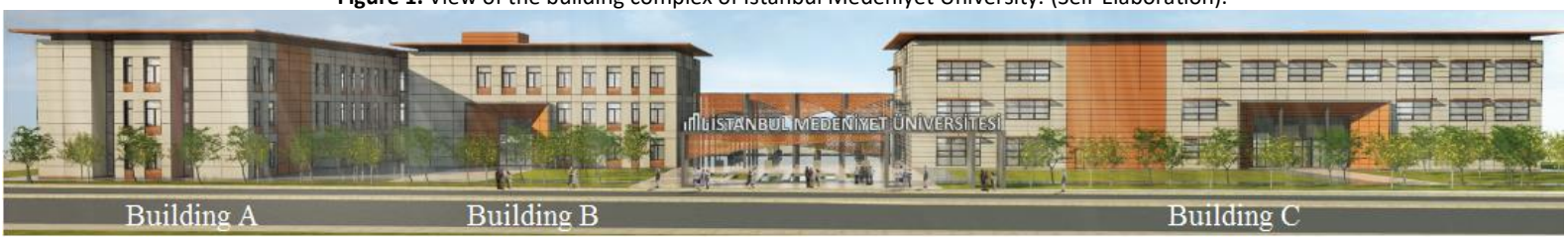

The building's structural system was designed as a combination of moment-resisting frames and eccentric braces. The slab system of the building is a composite slab formed by arched steel shell and reinforced concrete. The foundation of the building contains piles and single footings connected by link beams. Figure 2 illustrates the plan layout of the studied building on its second floor and its structural system with the used terminology through this study.

Figure 2. Plan layout and structural system of the studied building and used terminology. (Self-Elaboration).

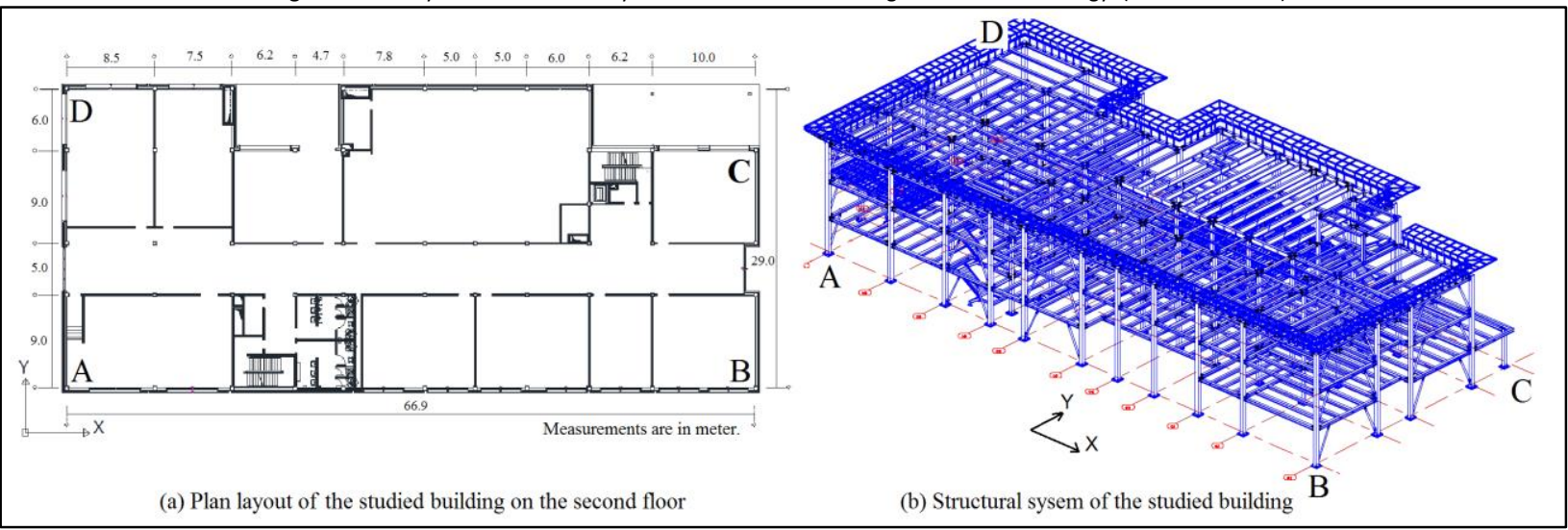

Since the dynamic characteristics of buildings change depending on the construction stages, acceleration measurements were taken from the studied building in each construction stage. Five uniaxial accelerometers containing Colibrys type sensor were located at the corner points of the building to collect vibration data along with longitudinal (X) and transversal (Y) directions. Four of the accelerometers were placed in two orthogonal directions at $A, B, C$, and $D$ corner points of the building as shown in Figure 2, and one reference accelerometer was located at the $B$ corner of the top floor. The linear full acceleration range of each sensor is $\pm 3 \mathrm{~g}$ and its noise level is $0.3 \mu \mathrm{grms} / \mathrm{VHz}$. One of the accelerometers was used as a reference sensor and located on the third story's B Corner, while the others were moved through other corners. Accelerations were gathered with 200 data per second and for each set, 20-minute records were taken which was long enough according to the Brincker criterion (Brincker, Ventura \& Andersen (2003)). As stated in the Brincker criterion, the time length of the recorded window should be at least equivalent to 1000 periods of the structure in practice to calculate an accurate spectral estimate.

The modal parameter estimation of a structural system based on its vibration response is very important and with this purpose, many signal processing techniques were developed and validated. The techniques are ranging from frequency domain algorithms based on the Fourier transform, such as peak pick (PP) and frequency domain decomposition (FDD), to time-domain algorithms, such as the Eigensystem realization algorithms (ERA) and the stochastic system identification (SSI) (Peeters \& De Roeck, 2001; Min \& Sun, 2013). In that respect, the literature on modal identification methodologies is vast and a literature survey is out of the scope of this study. In this study, the obtained records were analyzed by using the Matlab computer program and basically, the frequency domain representation for each measurement was obtained to see the dominant frequencies. No filtering was applied to the data and the frequency domain analyses were performed between 0 and $10 \mathrm{~Hz}$ which was deemed to be adequate for modal identification of the studied building.

\section{OMA during the construction of the building}

Construction stages of a steel building can be summarized as the montage of the beam and column elements, addition of braces, tightening the bolts, forming the slab system and addition of the partition walls, and other finishing, including heating, ventilating and air conditioning (HVAC) and communication cables. Although, these stages are expected to be successive in the construction site, generally they are performed together, especially when the high construction speed is required, just like the construction site of the studied building. For this reason, for the definition of the situation of 
the construction, on which OMA was performed, detailed explanations and figures were used together. Until the opening of the building, four sets of measurements were taken and analyzed. The situation of the building at each stage is presented in Figure 3.

Figure 3. The building at the a) 1st stage: before the completion of slabs; b) 2nd stage: after the completion of slabs; c) 3rd stage: completion of the partition walls; d) 4 th stage: completion of the construction. (Self-Elaboration)

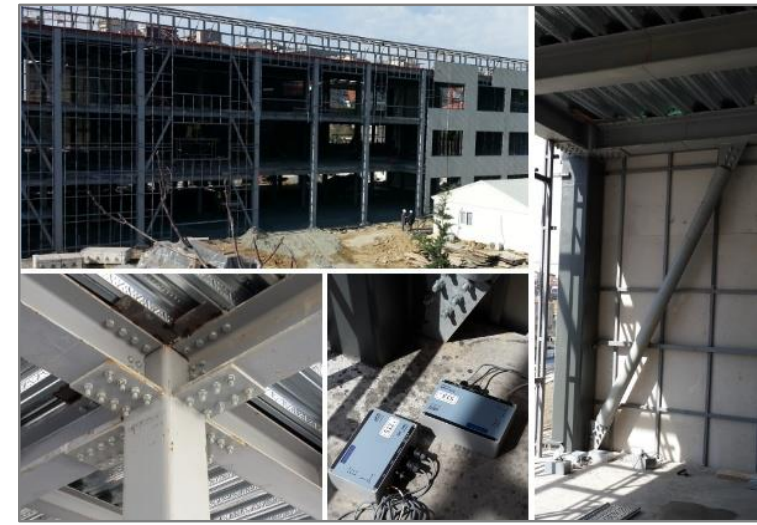

a)

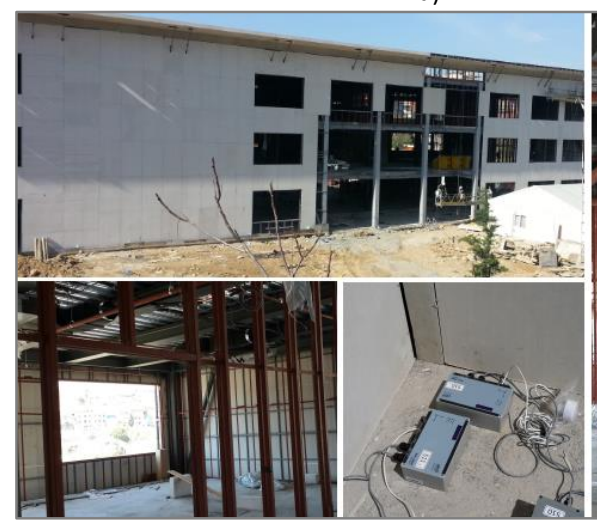

c)

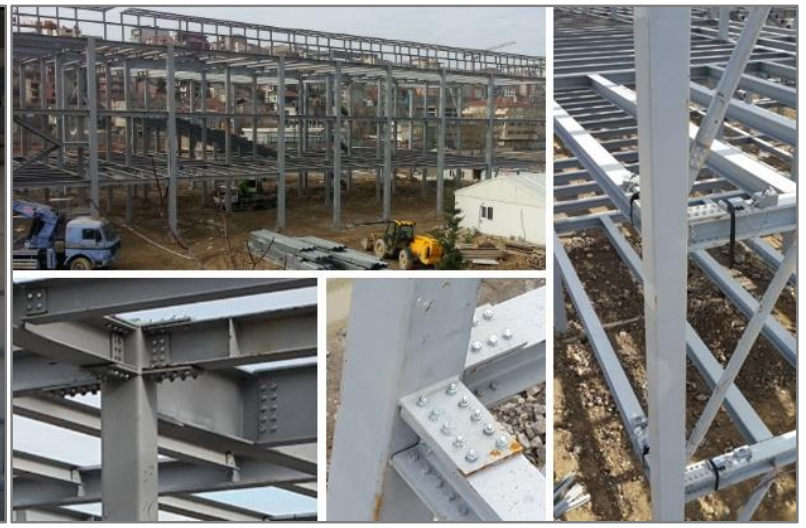

b)

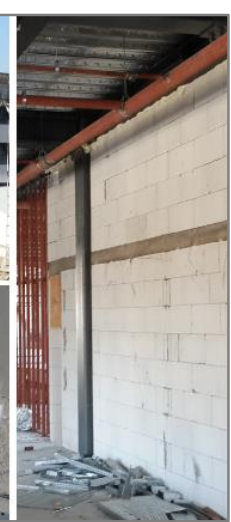

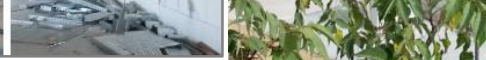

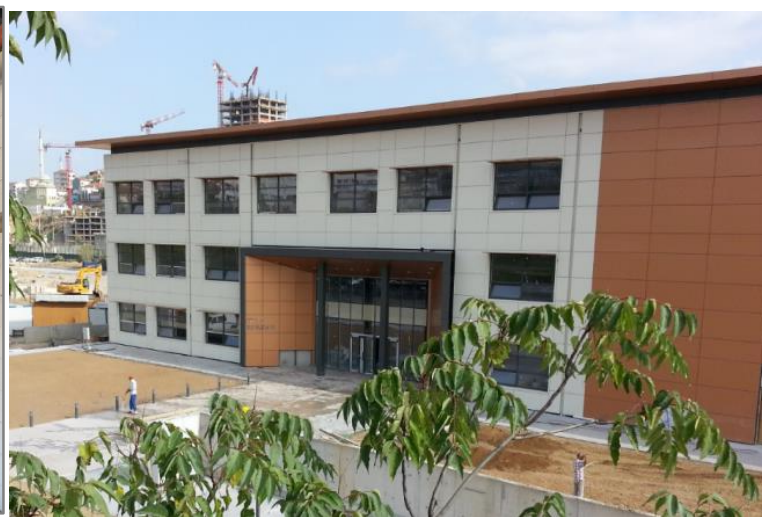

d)

For the case studies, the first vibration measurements were taken on 23.02.2015. The average temperature was recorded as $60 \mathrm{C}$. The entire frame elements were constructed including the braces except those in the front face. The majority of the bolts were not tightened (torqued) yet. Except for the girders, no slab elements were placed. In Figure $3(a)$, the building situation at this stage is shown. In each story, measurements were taken from three corners. During the measurements tightening of the bolts through the joints were progressing, but there were no significant force or vibration effect on the building except the wind and motorway traffic. In order to understand the dynamic characteristics of the building and see the dominant frequencies, fast Fourier transform (FFT) spectrums of the signals were taken from the 3rd floor, A, B and C corners along with $\mathrm{X}$ and $\mathrm{Y}$ directions of the building and detailed in Figure 4.

In the 1st stage analysis, as can be detected from Figure 4(a), corners A and B have the mutual peak frequencies along with $X$ direction, while corners $B$ and $C$ have the mutual frequency in the $Y$ direction. Moreover, $A$ and $C$ have no mutual frequency in $X$ or $Y$ directions. These findings simply prove that the girder beams could not supply the rigid floor diagram action, but frame action along with $X$ and $Y$ directions have been formed separately. Evaluation of the vibration records showed that the $A B$ frame of the building has many dominant modal frequencies starting from $1.48 \mathrm{~Hz}$ in the $X$ direction, while the $B C$ frame has a single dominant frequency of $3.62 \mathrm{~Hz}$ in the $Y$ direction. The 2 nd vibration measurements were performed on 03.04.2015. The temperature was recorded as 6oC. All of the frame elements with their connections have been completed. Concrete has been cast for the composite slab system of the building.

Partition walls have been started to be formed. Figure 3(b) shows the building in detail in the second stage. The mutual frequencies have been formed as the results of concrete casting for the composite slab system as seen. Frequencies of $1.6 \mathrm{~Hz}, 1.83 \mathrm{~Hz}$, and $2.27 \mathrm{~Hz}$ in both directions given in Figure 4(b) represent the first three modal vibrations of the building. 
Figure 4. FFT spectrums of the signals on the construction stages of the building in both directions: a) 1st stage; b) 2nd stage; c) 3rd stage; d) 4th stage. (Self-

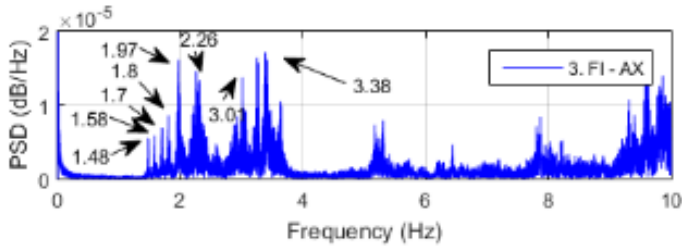
Elaboration)
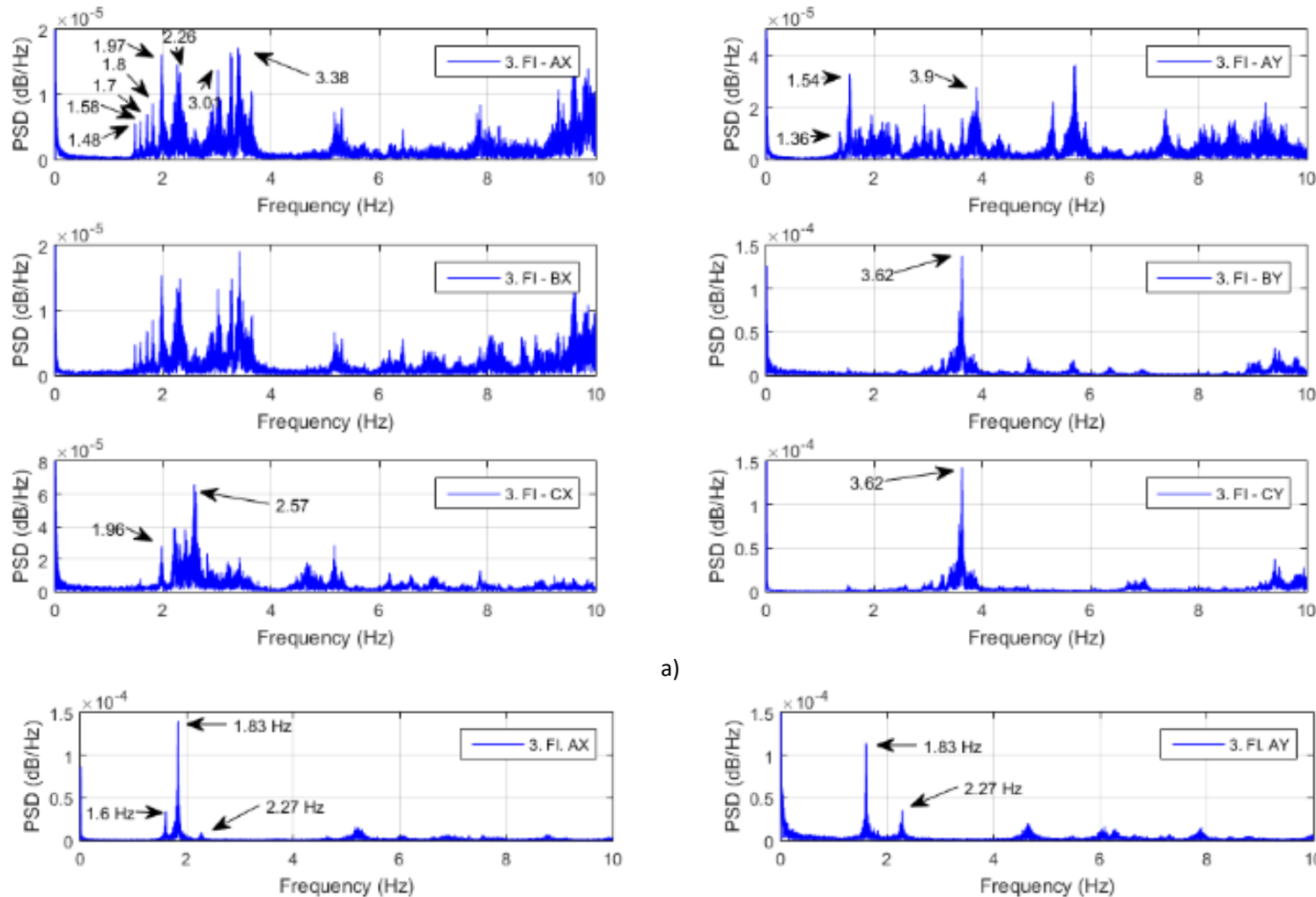

a)
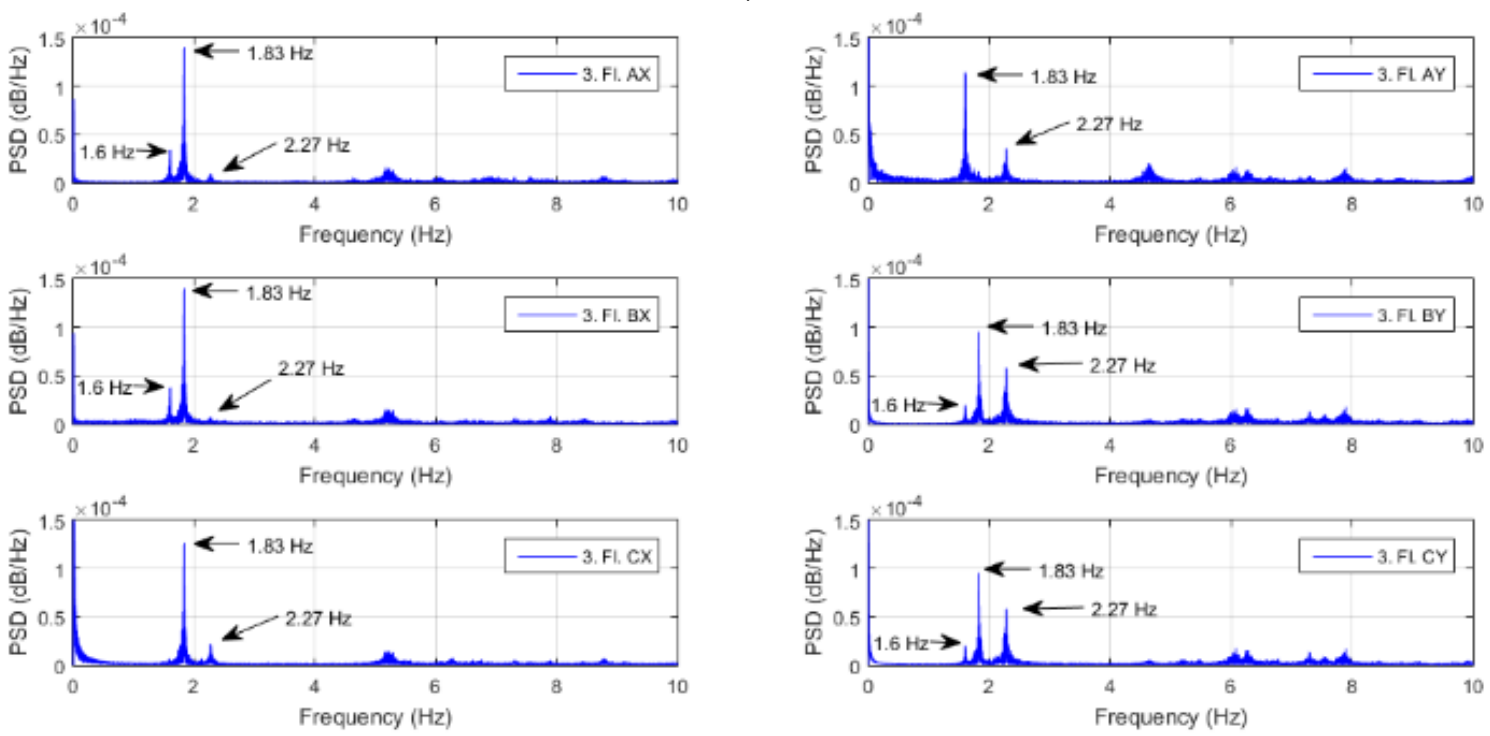

b)
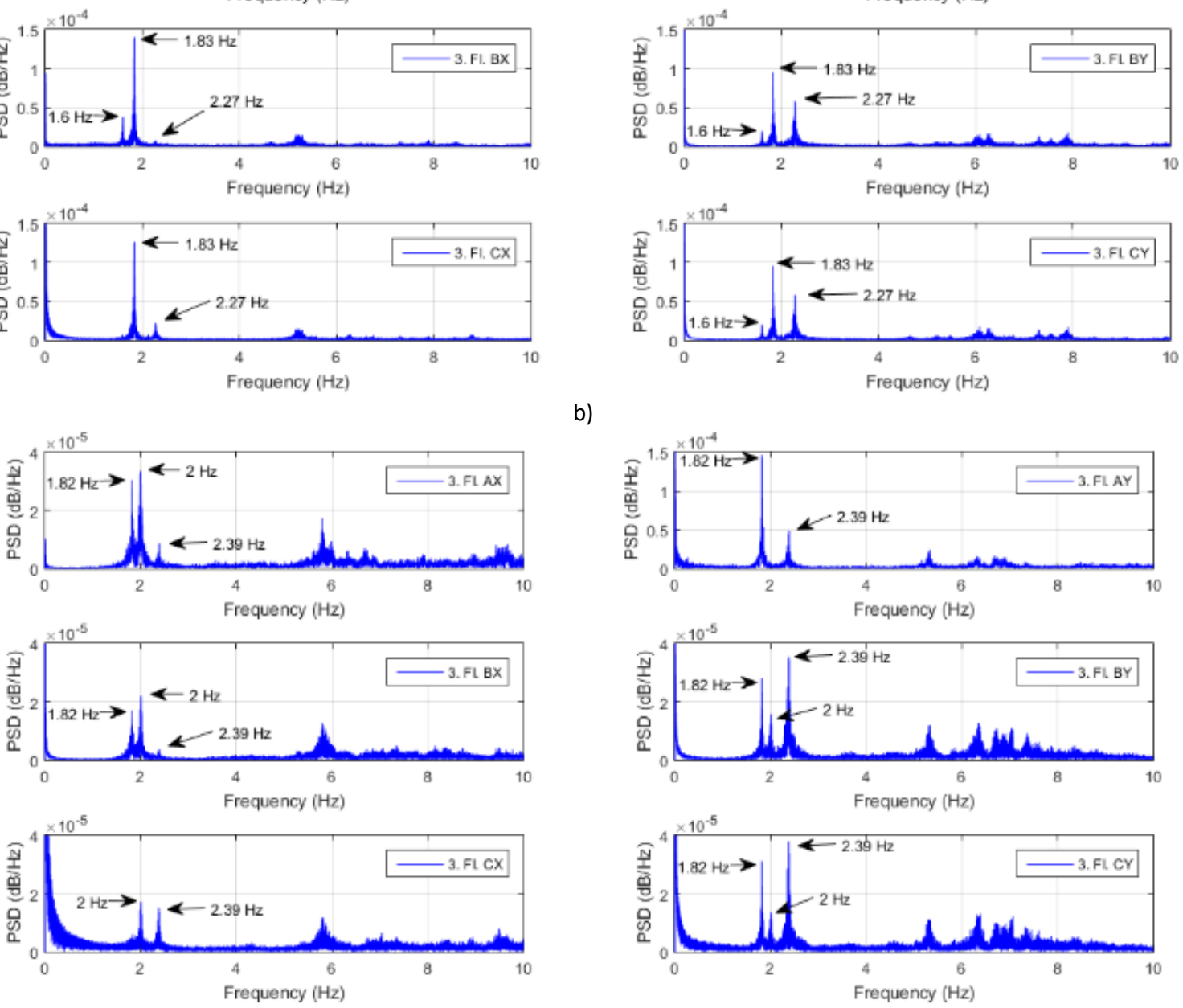

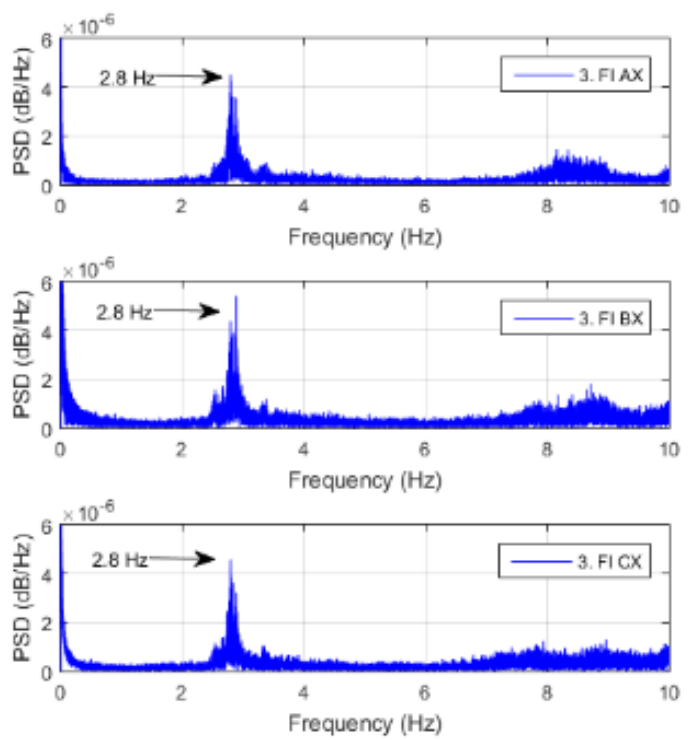
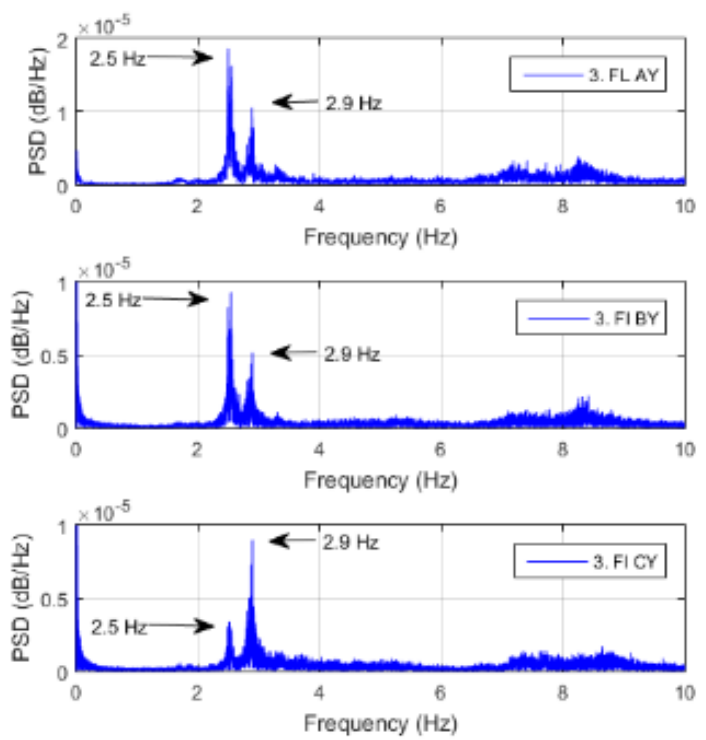

For the next step, the 3rd vibration measurements were performed on 24.04.2015. The temperature was recorded as $14 \mathrm{oC}$. In addition to the completed works of the second stage, the majority of the external and internal partition walls were completed. The HVAC and other cable equipment were in progress. The building at the 3rd stage is presented in Figure 3(c). As illustrated in Figure 4(c), the first three modal frequencies of the building have been determined as 1.82 $\mathrm{Hz}, 2 \mathrm{~Hz}$, and $2.37 \mathrm{~Hz}$. An increase in the modal frequencies of the building and the unchanged mode shapes are detectable compared to the previous stage. Therefore, stiffness effects of added partition walls are noted clearly.

The 4th stage of the building represents the completed form of the building including the nonstructural elements as shown in Figure 3(d). The temperature was recorded as 24oC. The measurements were taken on 02.09.2015, approximately after a month from the completion of all structural works. At this stage, the building was not under service yet. The dynamic properties of the building were determined. One mode in the $X$ direction and two modes in $Y$ direction were identified. According to the results presented in Figure 4(d), the first mode of the building was the simple movement along with $Y$ direction with a frequency of $2.5 \mathrm{~Hz}$. The second mode was identified as the simple movement along with $\mathrm{X}$ direction with a frequency of $2.8 \mathrm{~Hz}$ while the third mode was the movement along with $\mathrm{Y}$ direction with a frequency of $2.9 \mathrm{~Hz}$.

\section{OMA for the completed building}

As the main building of Istanbul Medeniyet University, Building C has been under service since 15.10.2015 and used for educational purposes. Moreover, with its two main halls, it hosts conferences, seminars, and university ceremonies where thousands of people participate. During the service of the building, OMAs are conducted to determine the dynamic characteristics of the building. The building was completed at this stage and the sensor locations were on the slabs at A, B, C and D corners as shown in Figure 2. The frequency-domain representation of the signals was taken from the third floor of the building where the vibrations were the highest and presented in Figure 5. When the 1st OMA was performed in the building, the temperature was recorded as 7oC. As pinpointed in Fig. 5(a), one dominant frequency is identified in the $X$ direction as $2.56 \mathrm{~Hz}$, while two dominant frequencies exist in the $Y$ direction as $2.3 \mathrm{~Hz}$ and $2.67 \mathrm{~Hz}$. A comparison of Figure 4(d) and Figure 5(a) proves the unchanged mode shapes and reduced frequencies in both directions. When the 2 nd OMA was performed, the temperature was recorded as $290 \mathrm{o}$.

As seen in Figure 5(b), the dominant frequency in the $X$ direction is $2.7 \mathrm{~Hz}$, while two dominant frequencies in the $Y$ direction are $2.45 \mathrm{~Hz}$ and $2.79 \mathrm{~Hz}$ proving the unchanged mode shapes and decreased frequencies with respect to previous OMA. The 3rd OMA was performed on 27.09.2017 when the opening ceremony of the academic year was performed. Therefore, the conference hall of the building was full. The temperature was recorded as $220 \mathrm{o}$. As detailed in Figure $5(\mathrm{c})$, the dominant frequency in the $X$ direction is $2.61 \mathrm{~Hz}$, while two dominant frequencies in the $Y$ direction are $2.46 \mathrm{~Hz}$ and $2.71 \mathrm{~Hz}$ proving the unchanged mode shapes and decreased frequencies with respect to previous OMA. Then, the 4th OMA was performed on 30.10.2017. The temperature was recorded as $160 \mathrm{C}$. Figure 5 (d) indicates that the dominant frequency in the $X$ direction is $2.61 \mathrm{~Hz}$, while two dominant frequencies in the $Y$ direction are $2.36 \mathrm{~Hz}$ and $2.68 \mathrm{~Hz}$ proving the unchanged mode shapes and decreased frequencies in only $\mathrm{Y}$ direction with respect to previous OMA. 
The 5th OMA was performed on 27.12.2017. The temperature was recorded as $130 \mathrm{oC}$. As can be seen in Figure 5(e), the dominant frequency in the $X$ direction is $2.54 \mathrm{~Hz}$, while two dominant frequencies in the $\mathrm{Y}$ direction are $2.3 \mathrm{~Hz}$ and 2.64 $\mathrm{Hz}$ proving the unchanged mode shapes and decreased frequencies in only $Y$ direction with respect to previous OMA. Finally, the 6th OMA was performed on 28.12.2017 when a conference speech is in progress. Approximately $60 \%$ of the conference hall was full of audiences. The temperature was recorded as $140 \mathrm{C}$. As presented in Figure 5(f), the dominant frequency in the $X$ direction is $2.51 \mathrm{~Hz}$, while two dominant frequencies in the $Y$ direction are $2.26 \mathrm{~Hz}$ and $2.68 \mathrm{~Hz}$ proving the unchanged mode shapes and decreased frequencies in only $\mathrm{Y}$ direction with respect to the previous OMA.

Figure 5. FFT spectrums of the signals derived in both directions in the stages of OMA in the completed building: a) 1st stage; b) 2nd stage; c) 3rd stage; d) 4th stage; e) 5 th stage; f) 6th stage. (Self-Elaboration).
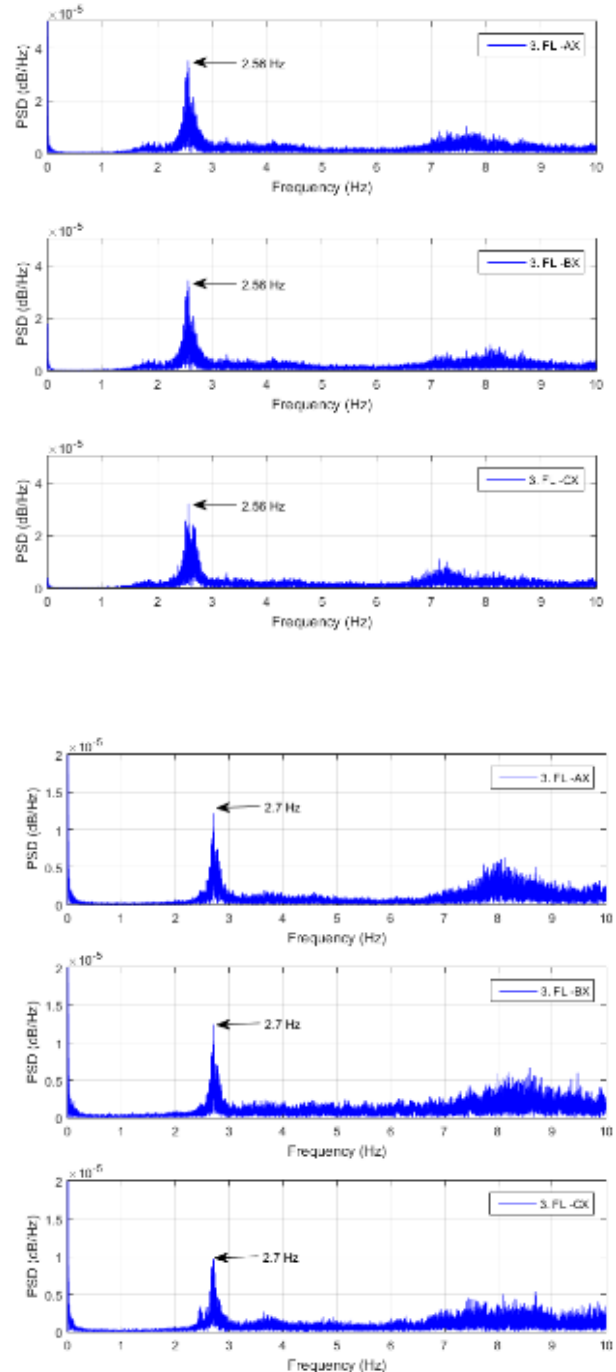
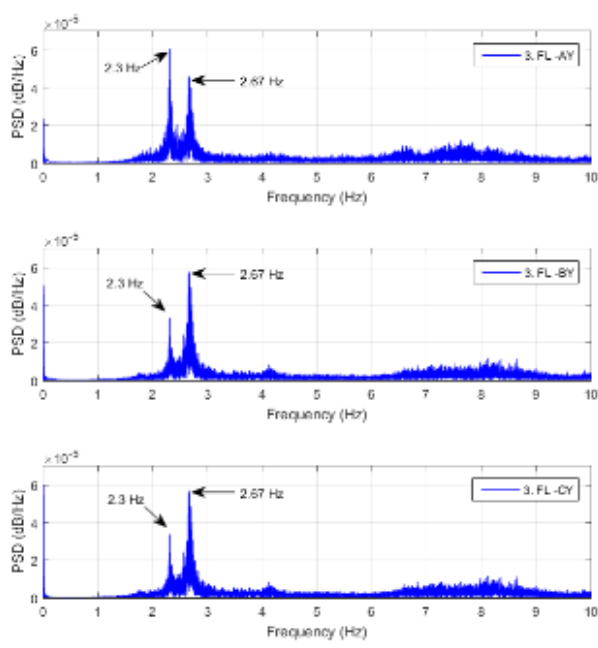

a)
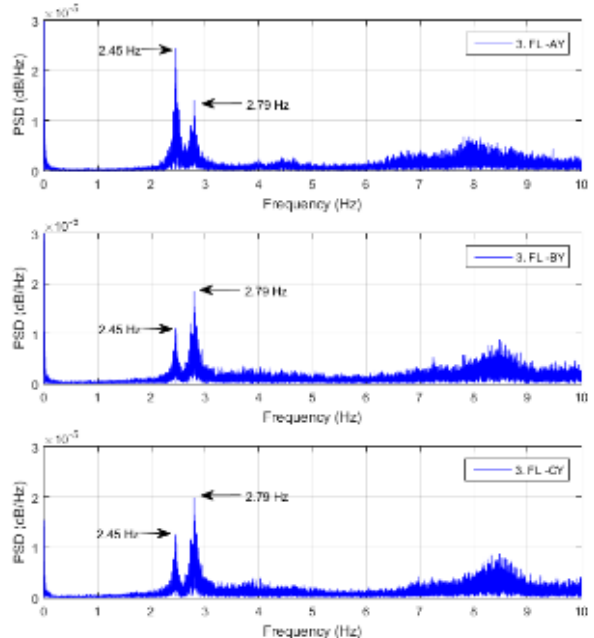

b) 

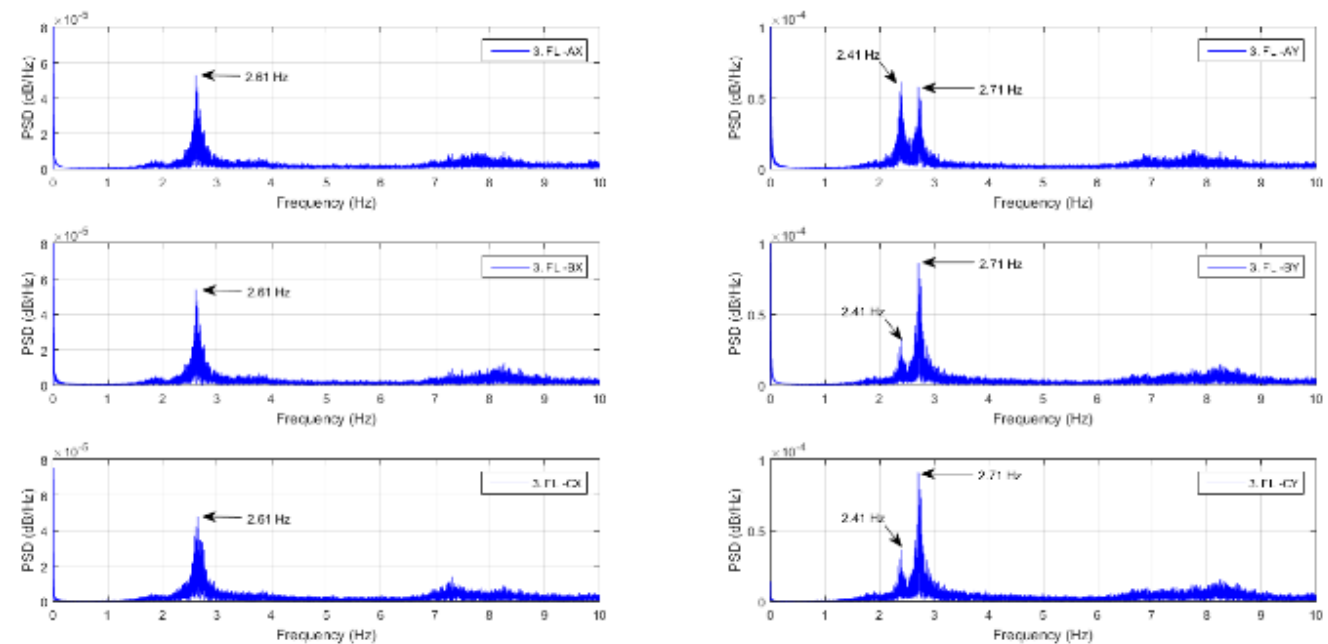

c)
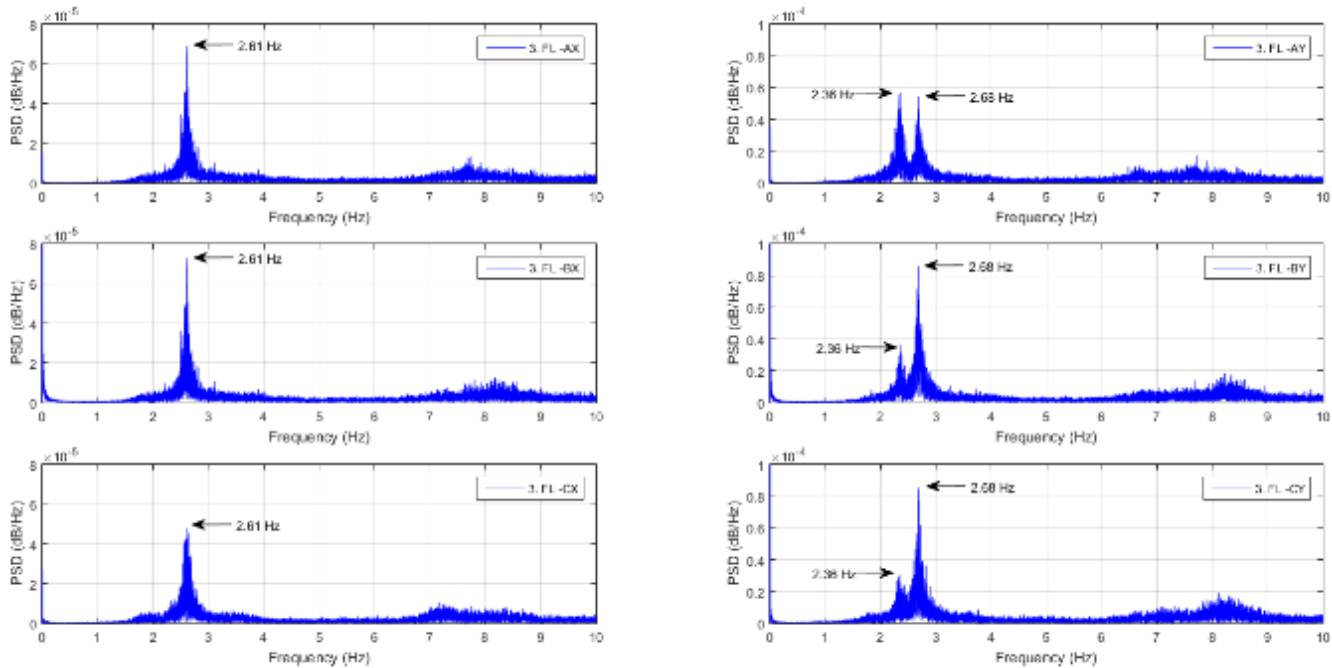

d)
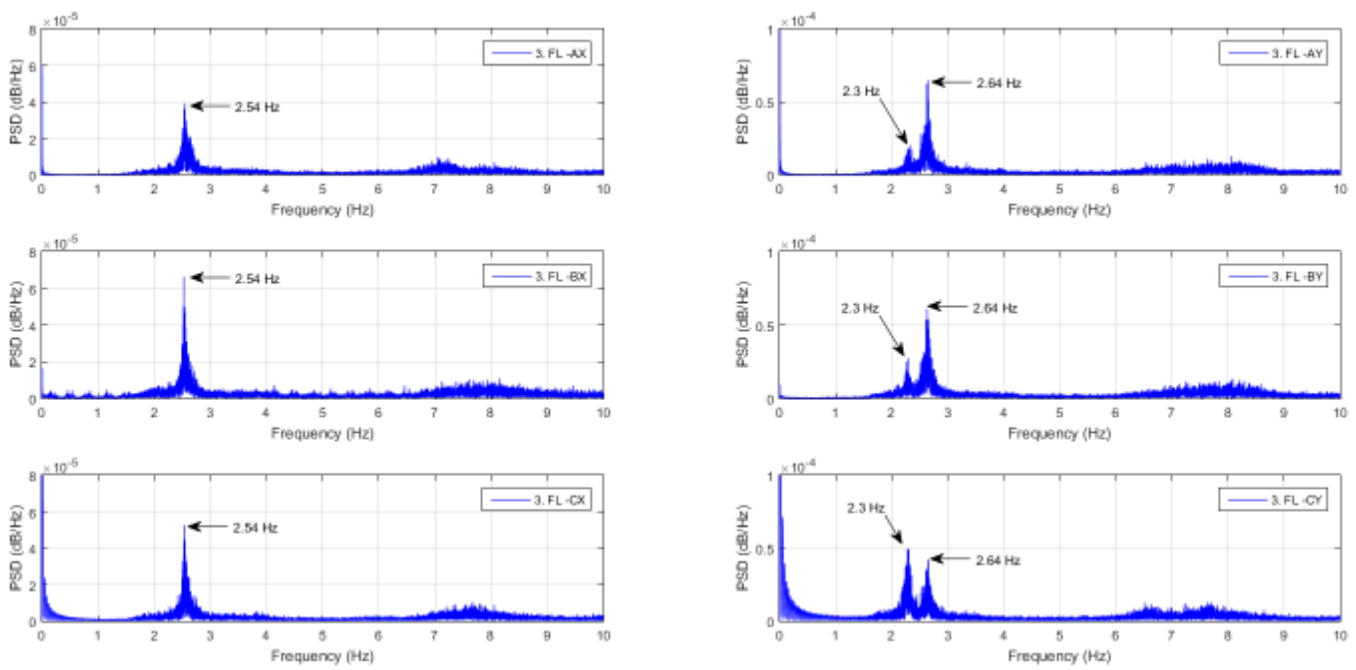

e) 

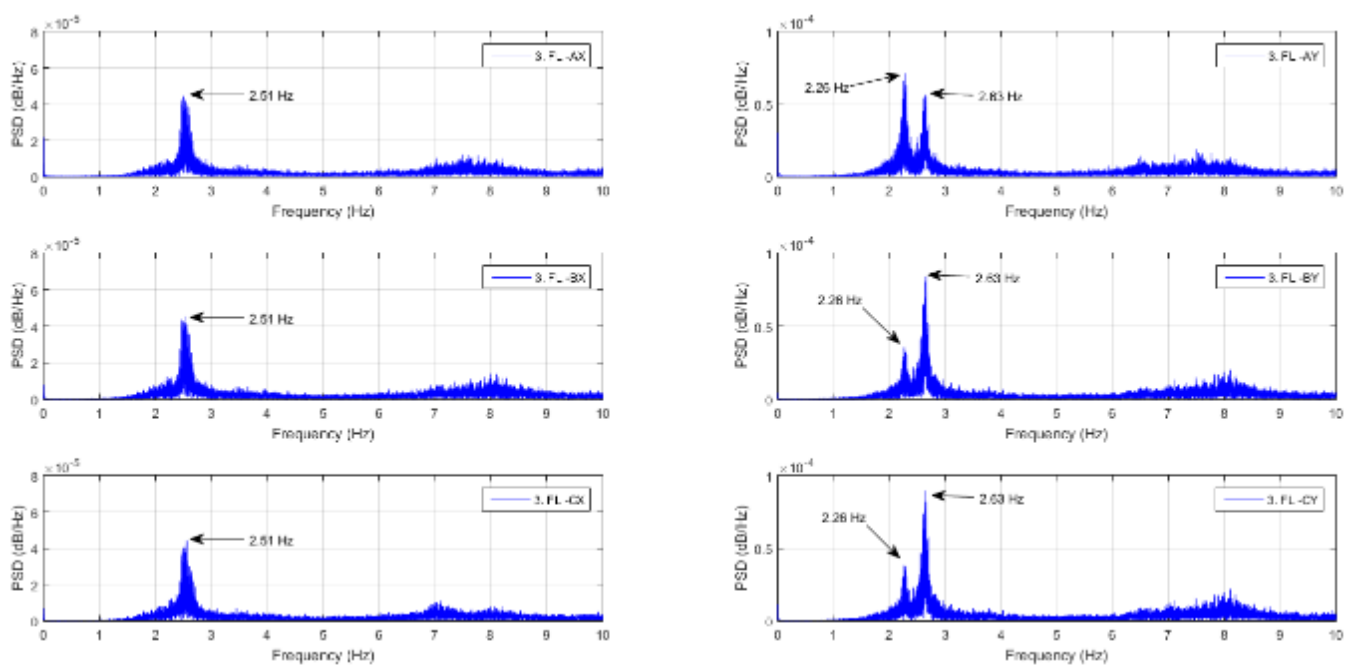

f)

Results and discussion

\section{Evaluation of the results of OMA for the building under use}

The results of the OMA, performed after the use of the studied building as an educational center, are summarized in Table 1. The evaluation of these results can reveal the effects of ambient temperature and live load on the dynamic properties of steel buildings. The following headings are devoted to these subjects.

Table 1. Summary of the results of OMA. (Self-Elaboration).

\begin{tabular}{|c|c|c|c|c|c|c|}
\hline $\begin{array}{l}\text { OMA } \\
\text { No }\end{array}$ & Date & $\begin{array}{l}\text { Temperature } \\
\left({ }^{\circ} \mathrm{C}\right)\end{array}$ & $\begin{array}{l}\text { Load rate, related to service of the } \\
\text { building }\end{array}$ & $\begin{array}{l}\mathrm{F} 1-\mathrm{Y} \\
(\mathrm{Hz})\end{array}$ & $\begin{array}{l}\mathrm{F} 2-\mathrm{X} \\
(\mathrm{Hz})\end{array}$ & $\begin{array}{l}\mathrm{F} 3-\mathrm{Y} \\
(\mathrm{Hz})\end{array}$ \\
\hline 1 & 24.01.2017 & 7 & $\begin{array}{l}\text { The building is used under its normal } \\
\text { function. No excessive service loads }\end{array}$ & 2.3 & 2.56 & 2.67 \\
\hline 2 & 10.08 .2017 & 29 & $\begin{array}{l}\text { The building is used under its normal } \\
\text { function. No excessive service loads }\end{array}$ & 2.45 & 2.7 & 2.79 \\
\hline 3 & 27.09.2017 & 22 & $\begin{array}{l}\text { The building hosts the academic } \\
\text { opening ceremony of the university. } \\
\text { The conference hall is full. }\end{array}$ & 2.41 & 2.61 & 2.71 \\
\hline 4 & 30.10 .2017 & 16 & $\begin{array}{l}\text { The building is used under its normal } \\
\text { function. No excessive service loads }\end{array}$ & 2.36 & 2.61 & 2.68 \\
\hline 5 & 27.12.2017 & 13 & $\begin{array}{l}\text { The building is used under its normal } \\
\text { function. No excessive service loads }\end{array}$ & 2.3 & 2.54 & 2.64 \\
\hline 6 & 28.12.2017 & 14 & $\begin{array}{l}\text { The building hosts a conference speech. } \\
\text { Half of the conference hall is full. }\end{array}$ & 2.26 & 2.51 & 2.63 \\
\hline
\end{tabular}

\section{The effects of ambient temperature on the dynamic frequencies}

In order to reveal the effects of the ambient temperature on the dynamic properties of the steel buildings, $1 \mathrm{st}$, $2 \mathrm{nd}$, $4 \mathrm{th}$ and 5th OMA results given in Table 1 should be compared because these analyses are performed under the same level of service load which is another effective property on the dynamic frequencies. The frequency values show that they increase with the increase in ambient temperature. Figure 6 summarizes the relationship between the ambient temperature and dynamic frequencies of the studied building. Three parallel lines prove the same response of the modal frequencies to ambient temperature. 


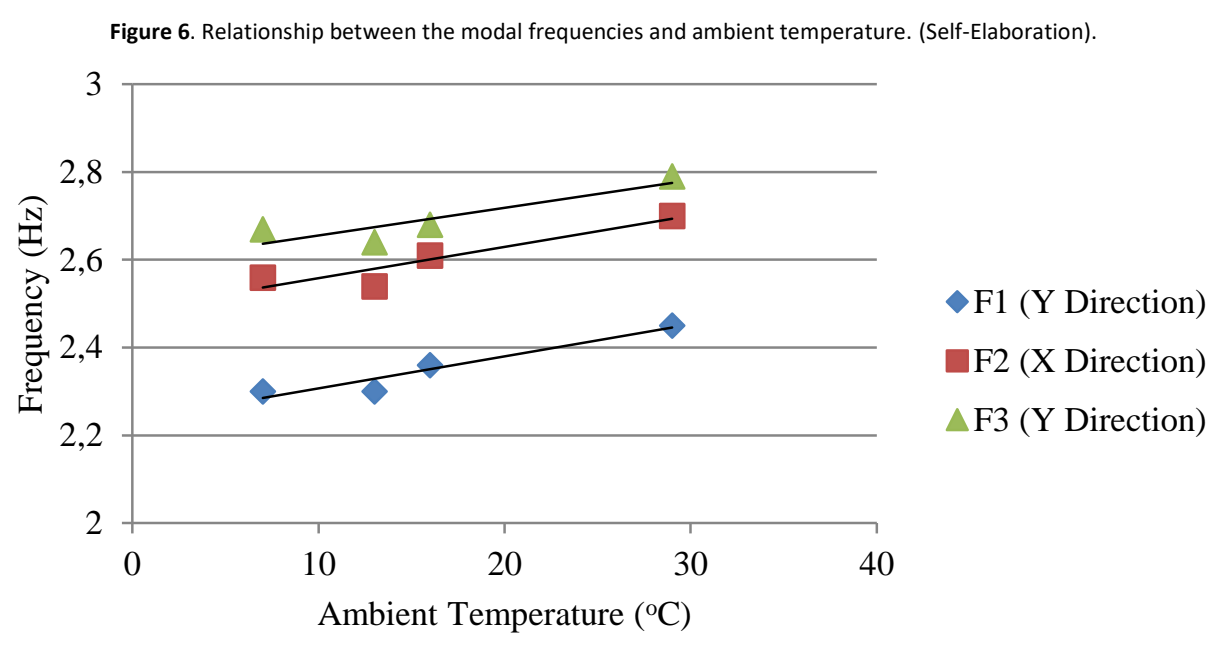

The effects of service loads on the dynamic frequencies

In order to determine the effects of service loads on the dynamic behavior of the studied building, the 5th and 6th OMA are compared, since the measurements were taken under the same level of temperature and different service loads. The difference between the service loads stems from the use of the conference hall, located on the first and the second floor of the building. As it is seen on the respective there are slight decreases in the modal frequencies. The first modal frequency decreased to $2.26 \mathrm{~Hz}$ from $2.30 \mathrm{~Hz}$, the second modal frequency decreased to $2.51 \mathrm{~Hz}$ from $2.54 \mathrm{~Hz}$, and the third modal frequency decreased to $2.63 \mathrm{~Hz}$ from $2.64 \mathrm{~Hz}$ due to live load increase due to the participant of the conference. Because of the basic relationship shown in Equation 1, where $f$ is frequency, $k$ is stiffness and $m$ is mass, any increase in the mass causes a decrease in the frequency. Figure 7 summarized the effects of service load on the dominant frequencies of the studied building.

$$
f=\frac{1}{2 \pi} \sqrt{\frac{k}{m}}
$$

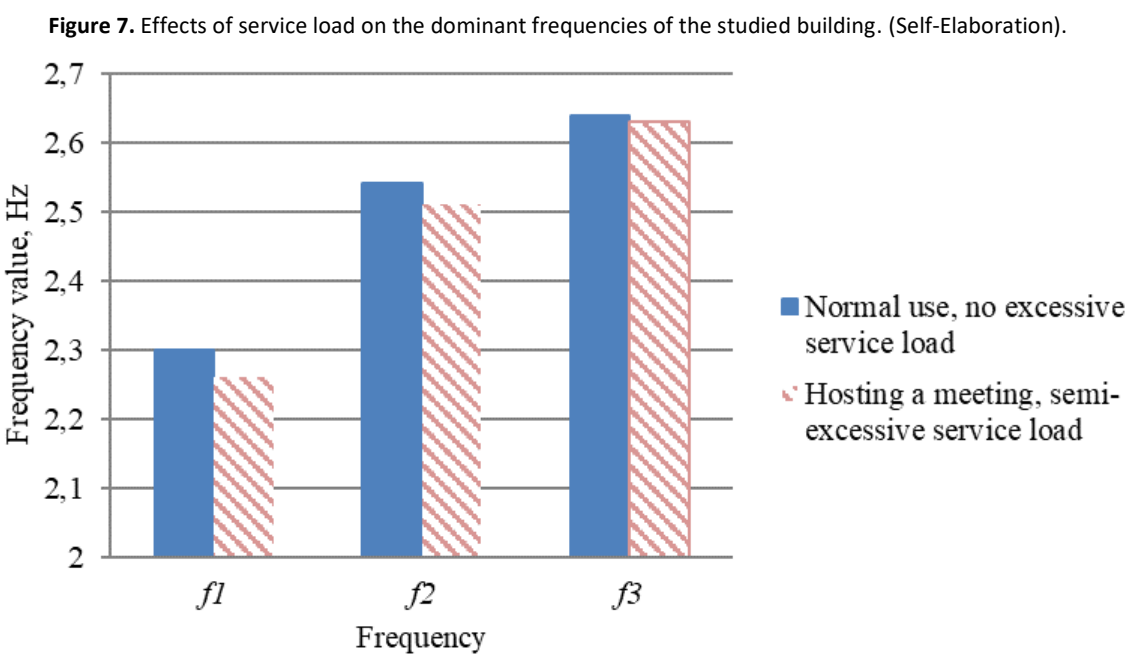

The results of the 3rd OMA may seem to be more appropriate to evaluate the live load effects since it is performed when the conference hall is full. However, the ambient temperature during the 3rd OMA is not close to the temperature of other events. For this reason, the results of the 3rd OMA is not used to extract a general finding, but it is presented as a case. 


\section{Mode shape of the studied building}

Modal displacements are proportional to the square root of the power density (PSD) of the signals at each dominant frequency. The mode shapes of the building can be identified by scaling the square root of the PSD magnitudes with a reference accelerometer (Inman, 2013). For the extraction of the mode shapes, the measurements taken on 27.12 .2017 when the building was used under its normal function and there were no excessive service loads have been used. PSD of the records taken from 1st, 2nd, and 3rd floors, B corner, have been detailed in Figure 8 for both directions and the determined mode shapes of the completed building are presented in Figure 9.
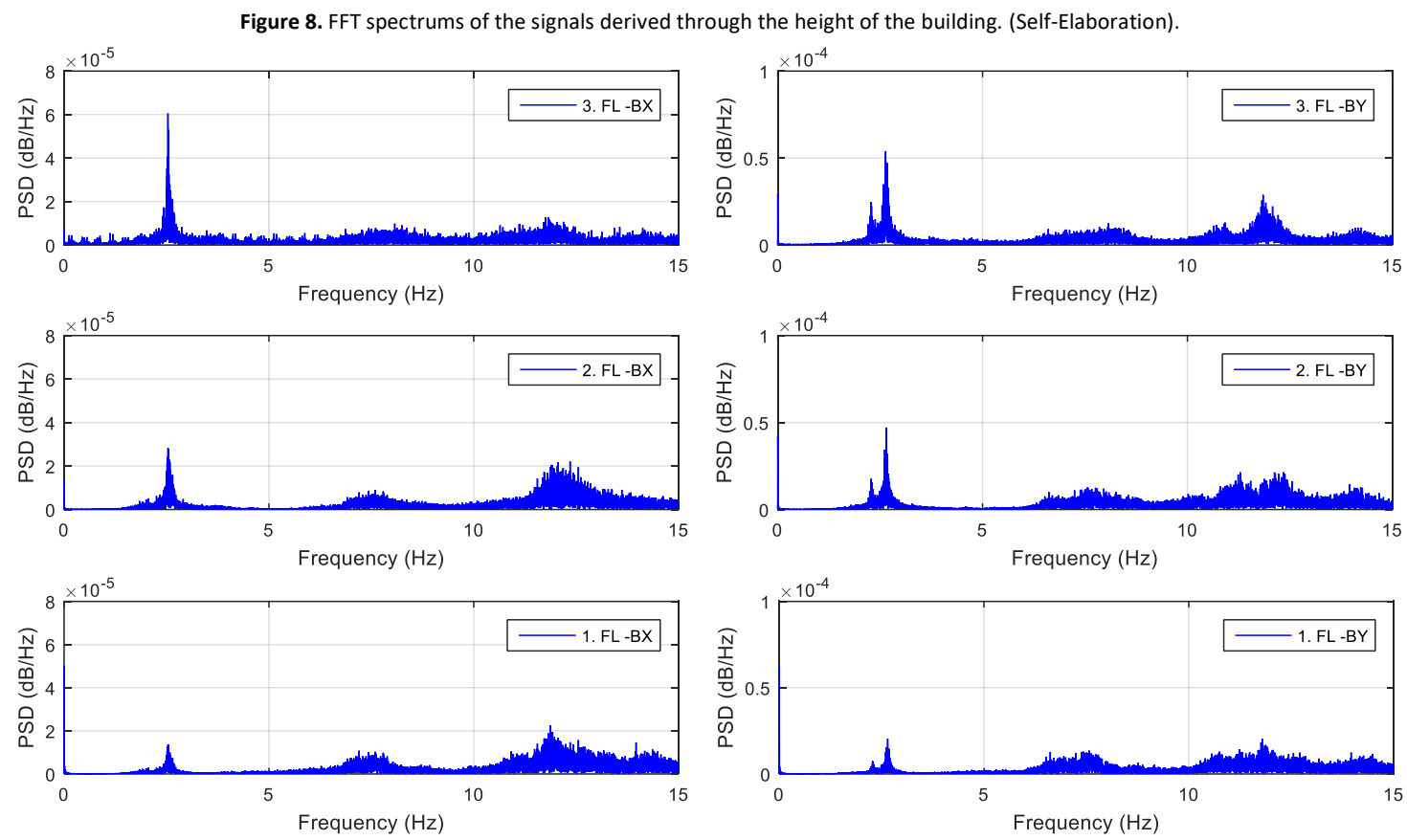

Figure 9. Extracted mode shapes of the studied building. (Self-Elaboration).
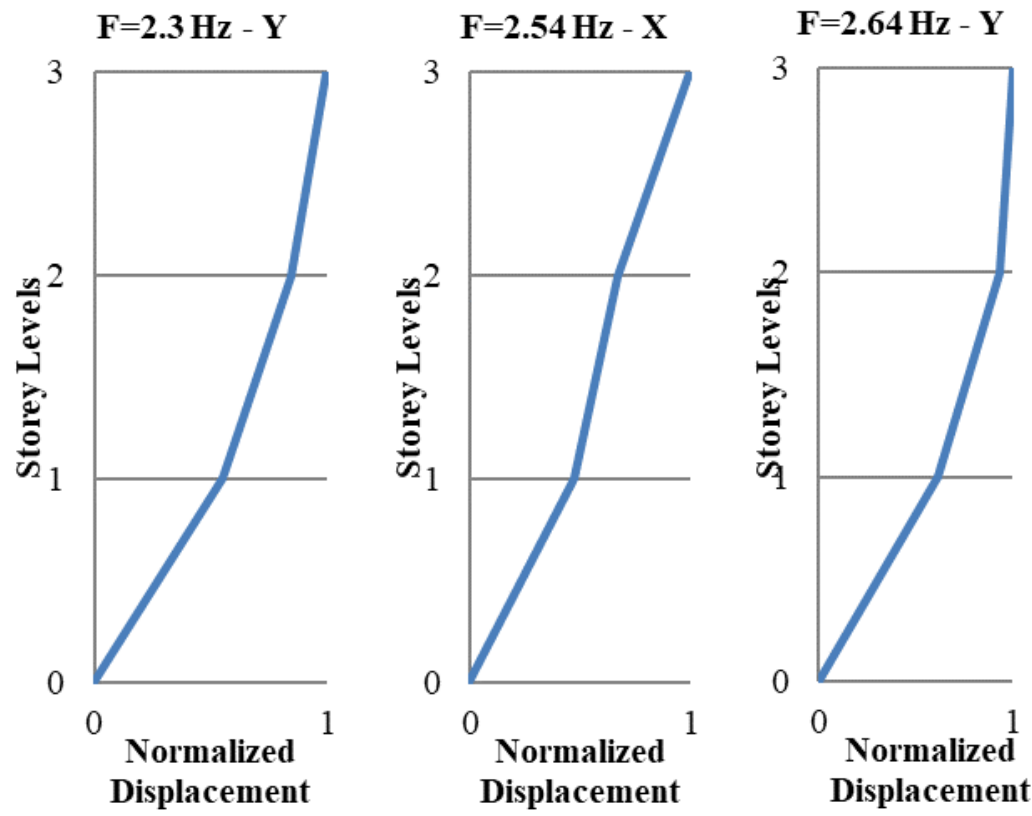

The numerical model of the building and dynamic analysis

Numerical dynamic analyses of the building have been performed with the finite element model of the building, constructed in the design stage. SAP2000 computer package has been used. Frame elements were used for the structural columns, beams, girder, and braces whereas shell elements used for the composite slab system. However, the mass induced by live load has been altered to reflect the existing condition of the building in which the experimental 
modal analysis was performed on the last stage. Rigid diaphragm property has not been assigned to the floors. Eigenvalue analysis has been performed and the dynamic properties of the building are shown in Table 2 . As can be seen from the mass participation ratios, the first 3 modes were in $\mathrm{Y}, \mathrm{X}$ and $\mathrm{X}$ directions, respectively.

Table 2. Numerically obtained modal frequencies and mass participations. (Self-Elaboration).

\begin{tabular}{ccccccc} 
Mode & Table 2. Numerically obtained modal frequencies and mass participations. (Self-Elaboration). \\
number & $\begin{array}{c}\text { Period } \\
(\mathrm{Sec})\end{array}$ & $\begin{array}{c}\text { Frequency } \\
(\mathrm{Hz})\end{array}$ & \multicolumn{2}{c}{ Mass participation ratio } & Sum of mass participation ratio \\
\cline { 5 - 7 } 1 & 0.66 & 1.51 & 0.00 & 0.81 & $\mathrm{X}$ & $\mathrm{Y}$ \\
2 & 0.61 & 1.64 & 0.65 & 0.00 & 0.00 & 0.81 \\
3 & 0.53 & 1.90 & 0.22 & 0.00 & 0.87 & 0.82 \\
4 & 0.40 & 2.47 & 0.00 & 0.00 & 0.87 & 0.82 \\
5 & 0.40 & 2.48 & 0.00 & 0.00 & 0.87 & 0.82 \\
6 & 0.27 & 3.75 & 0.00 & 0.00 & 0.87 & 0.82 \\
7 & 0.24 & 4.25 & 0.00 & 0.11 & 0.87 & 0.82 \\
8 & 0.23 & 4.35 & 0.00 & 0.03 & 0.87 & 0.93 \\
9 & 0.22 & 4.54 & 0.11 & 0.00 & 0.97 & 0.96 \\
10 & 0.21 & 4.75 & 0.00 & 0.00 & 0.97 & 0.96 \\
\hline
\end{tabular}

Since rigid diaphragm property has not been used, some of the modes have been developed by the movement of individual elements in which global dynamic behavior could not be presented. As a result, the mass participation of these modes is such small values that should be excluded for the interpretation of the structural behavior of the studied building (Mode 4, 5, etc). It is seen that after nine modes $96 \%$ of the total mass has been calculated. The first three modes of the building represent the global behavior of the building. The first mode was obtained as the movement of the building in the $Y$ direction $(1.51 \mathrm{~Hz}$ ), the second mode was the movement of the building in the $\mathrm{X}$ direction (1.64 $\mathrm{Hz}$ ) and the third mode is the movement of the building in the $X$ direction $(1.90 \mathrm{~Hz})$.

The other modes with smaller mass participation values i.e., modes 7, 8 and 9, represent the partial movement of slab girders which are stemming from the modeling. Figure 10 shows the first three and sixth modes of the building. As can be seen, the sixth mode of the building is the vertical movement of the slab in front of the building which cannot be determined by the experimental analysis.
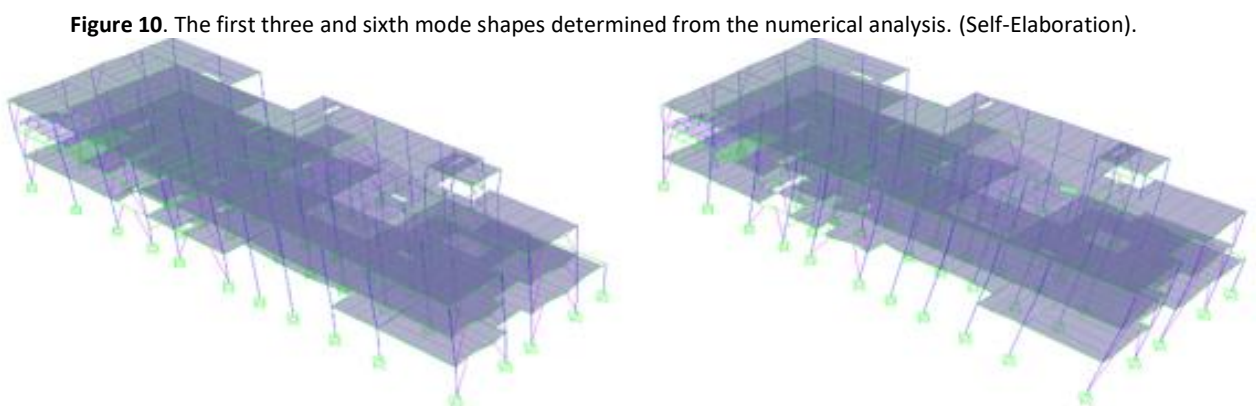

Mode 1: Movement in $\mathrm{Y}$ direction

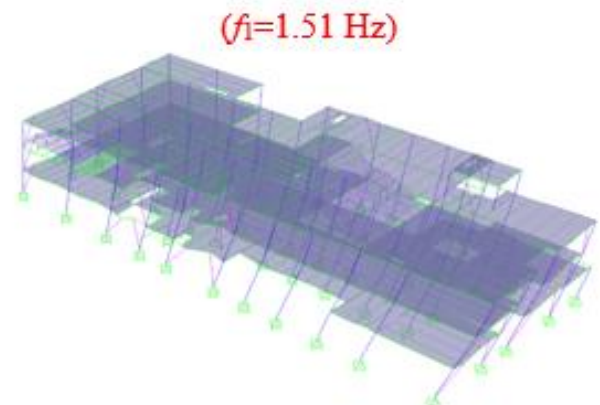

Mode 3: Movement in $\mathrm{X}$ direction

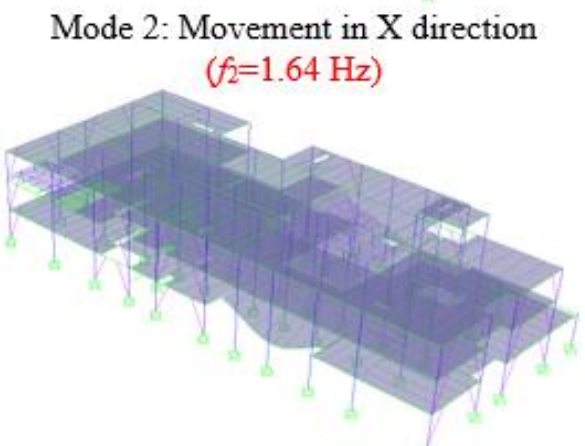
$\left(f_{3}=1.90 \mathrm{~Hz}\right)$

Mode 6: Movement of slab in $\mathrm{Z}$ direction $\left(f_{6}=3.75 \mathrm{~Hz}\right)$ 
A comparison of the experimental and numerical modes can be performed via the first three modes. As summarized in Table 3, these results prove that the numerical model has estimated the first and the second mode the building with smaller frequencies. Moreover, the third mode has been determined as the mode is determined in the $X$ direction is miscalculated. The main reason for the underestimated frequencies and the miscalculated third mode is probably the partition walls that are not included in the numerical model. The inclusion of the partition walls into the numerical model can increase the rigidity thereby the frequency of the building. In that respect, the closer modal frequencies can be obtained for the numerical and experimental results. However, modeling of the partition walls requires detailed geometry, mechanical properties, and connection details for the applied composite wall system. For these reasons, the author did not intend to model the partition walls.

Table 3. Determined dynamic properties of the studied building by OMA and numerical analysis. (Self-Elaboration).

\begin{tabular}{ccccc} 
& \multicolumn{2}{c}{ Table 3. Determined dynamic properties of the studied building by OMA and numerical analysis. (Self-Elaboration). } \\
\hline $\begin{array}{c}\text { Mode } \\
\text { Number }\end{array}$ & $\begin{array}{c}\text { Frequency } \\
(\mathrm{Hz})\end{array}$ & Mode Shape & $\begin{array}{c}\text { Frequency } \\
(\mathrm{Hz})\end{array}$ & Numerical Analysis \\
\hline 1 & 2.30 & $\begin{array}{c}\text { Movement along with Y } \\
\text { direction }\end{array}$ & 1.51 & $\begin{array}{c}\text { Movement along with Y } \\
\text { direction }\end{array}$ \\
2 & 2.54 & $\begin{array}{c}\text { Movement along with X } \\
\text { direction }\end{array}$ & 1.64 & $\begin{array}{c}\text { Movement along with X } \\
\text { direction }\end{array}$ \\
3 & 2.64 & $\begin{array}{c}\text { Movement along with Y } \\
\text { direction }\end{array}$ & 1.90 & $\begin{array}{c}\text { Movement along with X } \\
\text { direction }\end{array}$ \\
\hline
\end{tabular}

This study presents the results of OMA that has been applied to a steel building during its construction period and after its completion. The dynamic properties of the structure have been recorded and monitored using accelerometers in different construction stages for about a year. After the construction is completed, in order to diagnose the changes in the modal characteristics of the building with respect to the temperature and service loads, dynamic tests are applied at different times. Also, numerical analysis is performed and the results are compared with the results that are experimentally identified to see the differences for updating the model. The results of in-situ monitoring are analyzed and the experimental results are used for the calibration of the model. To sum up, the findings of the study are divided into three groups as given below.

1. During its construction, the variation of its dynamic properties is monitored to evaluate the effects of the structural works. It is stated that:

- When the columns and beams (including the slab girders) are constructed with not tightened bolds, overall structural behavior does not take form.

- Overall structural behavior takes form after the completion of the slab system with reinforced concrete.

- Experimental modal analysis of the completed building has given the first mode of the building as simple movement along with $\mathrm{Y}$ direction $(2.5 \mathrm{~Hz})$, the second mode as the simple movement along with $\mathrm{X}$ direction $(2.8 \mathrm{~Hz})$ and the third mode is the movement along with $Y$ direction $(2.9 \mathrm{~Hz})$. Up to $10 \mathrm{~Hz}$, no other dominant frequency has been verified.

2. After the completion of the building, the effects of ambient temperature and service loads have been investigated by applying OMA in different conditions. The comparison of OMA results showed that:

- The increase in the ambient temperature results in increases in the modal frequencies. The mode shapes remain the same.

- $\quad$ Any increase in the service loads results in a decrease in the modal frequencies.

3. The numerical analysis has been performed for the final stage of the building with the purpose of evaluating the reliability of the numerical model in predicting the dynamic behavior of the building. As a result of the numerical analysis, dynamic properties are obtained and the consistency between the numerical and experimental results is compared. The findings proved that;

- Numerical modal analysis has given the first mode of the building as the movement in the $Y$ direction (1.51 $\mathrm{Hz})$, the second mode as the movement in the $X$ direction $(1.64 \mathrm{~Hz})$, and the third mode as the movement in the $X$ direction $(1.90 \mathrm{~Hz})$ again. The first ten modes of the building are verified with frequencies less than $5 \mathrm{~Hz}$. 
- Some of the numerically verified modes are grasped as unimportant since they do not represent the general structural behavior of the building. These modes seem to have small mass participation ratio in numerical analysis and cannot be determined by OMA unless specific local measurements are taken.

- The discrepancy between the experimental and numerical results has mainly been predicated on the exclusion of the partition walls into the numerical model.

Acknowledgements

This study has been performed with the support of the projects TUBITAK-214M235 and IMU-BAP-FBA-2013-448. The authors also acknowledge the help of Yasir Korkusuz, Tarik Tufan, and Mesut Geren during the measurements.

\section{References}

Aras, F. (2016). Frequency variation in construction stages and model validation for steel buildings. Steel and Composite Structures, 22(3), 647-662. https://doi.org/10.12989/scs.2016.22.3.647

Aras, F. (2016). Ambient and forced vibration testing with numerical identification for RC buildings. Earthquake and Structures, 11(5), 809-822. https://doi.org/10.12989/eas.2016.11.5.809

Bayraktar, A., Sevim, B., Altunışık, A.C., Türker, T. \& Adanur, S. (2008). Determination of blast vibration effects on the dynamic behaviour of the highway bridges using modal testing. 8th International Congress in Advances in Civil Engineering, Famagusta, North-Cyprus, 15-17 September 2008.

Brincker, R., Ventura, C., \& Andersen, P. (2003, February). Why output-only modal testing is a desirable tool for a wide range of practical applications. In Proc. International Modal Analysis Conference (IMAC) XXI, paper (Vol. 265), Kissimmee, Florida.

Brincker, R. \& Ventura, C. (2015). Introduction to operational modal analysis. Chichester, United Kingdom: John Wiley \& Sons Ltd.

Chellini, G., De Roeck, G., Nardini, L. \& Salvatore, W. (2010). Damage analysis of a steel-concrete composite frame by finite element model updating. Journal of Constructional Steel Research, 66, 398-411. https://doi.org/10.1016/j.jcsr.2009.10.004

Consuegra, F.A. \& Santos, C. (2015). Vibration analyses for the local and global evaluation of bridges as a tool for structural retrofit. Revista de la Construccion, 14(1), 16-22. https://doi.org/10.4067/\$0718-915X2015000100002

Gentile, C., Saisi, A. \& Cabboi, A. (2015). Structural identification of a masonry tower based on operational modal analysis. International Journal of Architectural Heritage, 9(2), 98-110. https://doi.org/10.1080/15583058.2014.951792

Inman, D.J. (2013). Engineering Vibration - 4th Edition. Prentice Hall, New Jersey.

Kudu, F.N., Uçak, Ş., Osmancikli, G., Türker, T. \& Bayraktar, A. (2015). Estimation of damping ratios of steel structures by Operational Modal Analysis method. Journal of Constructional Steel Research, 112, 61-68. https://doi.org/10.1016/j.jcsr.2015.04.019

Macdonald, J.H.G. \& Daniell, W.E. (2005). Variation of modal parameters of a cable-stayed bridge identified from ambient vibration measurements and FE modeling. Engineering Structures, 27, 1916-1930. https://doi.org/10.1016/j.engstruct.2005.06.007

Min, Z.H. \& Sun, L.M. (2013). Wavelet-based structural modal parameter identification. Structural Control Health Monitoring, 20, 121-138. https://doi.org/10.1002/stc.474

Ni, Y.C., Lu, X.L. \& Lu, W.S. (2017). Operational modal analysis of a high-rise multi-function building with dampers by a Bayesian approach. Mechanical Systems and Signal Processing, 86, 286-307. https://doi.org/10.1016/j.ymssp.2016.10.009

Peeters, B. \& De Roeck, G. (2001). Stochastic system identification for operational modal analysis: a review. Journal of dynamic systems measurement and control-transactions of the ASME, 123(4), 659-667. https://doi.org/10.1115/1.1410370

Sevim, B., Altunışık, A.C. \& Bayraktar, A. (2012). Earthquake behavior of Berke arch dam using ambient vibration test results. Journal of Performance of Constructed Facilities, 26(6), 780-792. https://doi.org/10.1061/(ASCE)CF.1943-5509.0000264

Shakib, H. \& Parsaeifard, N. (2011). Ambient vibration tests on a 19-story asymmetric steel building. Structural Engineering and Mechanics, 40(1), 111. https://doi.org/10.12989/sem.2011.40.1.001

Shiradhonkar, S.R. \& Shrikhande, M. (2011). Seismic damage detection in a building frame via finite element model updating. Computers \& Structures, 89(23-24), 2425-2438. https://doi.org/10.1016/j.compstruc.2011.06.006

Torkamani, M.A.M. \& Ahmadi, A.K. (1988). Stiffness identification of a tall building during construction period using ambient tests. Earthquake Engineering Structural Dynamics, 16(8), 1177-1188. https://doi.org/10.1002/eqe.4290160806

Türker, T., Kartal, M.E., Bayraktar, A. \& Muvafik, M. (2009). Assessment of semi-rigid connections in steel structures by modal testing. Journal of Constructional Steel Research, 65, 1538-1547. https://doi.org/10.1016/j.jcsr.2009.03.002

Türker, T. \& Bayraktar, A. (2011). Experimental and numerical investigation of brace configuration effects on steel structures. Journal of Constructional Steel Research, 67, 854-865. https://doi.org/10.1016/j.jcsr.2010.12.008 
Türker, T. \& Bayraktar, A. (2013). Finite element model calibration of steel frame buildings with and without brace. Journal of Constructional Steel Research, 90, 164-173. https://doi.org/10.1016/j.jcsr.2013.08.003

Zhang, F., Yang, Y., Xiong, H., Yang, J. \& Yu, Z. (2019). Structural health monitoring of a 250-m super-tall building and operational modal analysis using the fast Bayesian FFT method. Structural Control Health Monitoring, 26(8), e2383. https://doi.org/10.1002/stc.2383 